\title{
The Effect of Naloxone on the Hemodynamics of the Newborn Piglet with Septic Shock
}

\author{
RANDY R. MILLER, JAMES A. MENKE, NANCY B. HANSEN, DAVID L. ZWICK, \\ REX G. BICKERS, AND PHILIP $T$. NOWICKI \\ Departments of Pediatrics and Pathology, The Ohio State University and Children's Hospital, \\ Columbus, Ohio 43205
}

\begin{abstract}
Naloxone has been shown to reverse the hemodynamic sequelae of experimental septic shock in adult animal models. Its effectiveness in the newborn has not been studied. To further investigate the efficacy of naloxone, we instrumented 18 piglets for continuous measurement of mean arterial pressure, mean pulmonary arterial pressure, central venous pressure, heart rate, left ventricular pressure, contractility, cardiac output, and $\mathrm{O}_{2}$. Oxygen consumption, systemic vascular resistance, and pulmonary vascular resistance were calculated. Following a stabilization period, group B $\beta$-hemolytic Streptococci were infused over $30 \mathrm{~min}$. Following the infusion, naloxone $(1 \mathrm{mg} / \mathrm{kg}$ ) was given followed by a continuous infusion of $1 \mathrm{mg} / \mathrm{kg} / \mathrm{h}$ in nine treatment animals. Nine control animals were given an equal volume of saline. Both groups developed significant increases in mean pulmonary arterial pressure followed by a return to baseline. Oxygen consumption, cardiac output, contractility and mean arterial pressure decreased in both groups. Treatment with naloxone was associated with a cessation in the fall in the mean arterial pressure and the contractility. The difference in mean arterial pressure and contractility between groups was significant. The naloxone group had significantly improved 5-h survival. We speculate that naloxone may reverse some of the hemodynamic sequelae and improve survival in newborns with septic shock. (Pediatr Res 20: 707-710, 1986)
\end{abstract}

\section{Abbreviations}

CO, cardiac output

CVP, central venous pressure

$\mathrm{CaO}_{2}$, arterial oxygen content

$\mathrm{CpO}_{2}$, pulmonary arterial oxygen content

dP/dt, contractility

GBBS, group B $\beta$-hemolytic Streptococci

$\mathrm{HR}$, heart rate

LVEDP, left ventricular end-diastolic pressure

MAP, mean arterial pressure

PAP, mean pulmonary arterial pressure

PVR, pulmonary vascular resistance

SVR, systemic vascular resistance

$\mathrm{VO}_{2}$, oxygen consumption

Endogenous opioids (endorphins) may play an important role in the pathophysiology of septic shock (1). Although endorphins

Received October 7, 1985; accepted March 12, 1986.

Correspondence James A. Menke, M.D., Department of Pediatrics, Children's Hospital, 700 Children's Drive, Columbus, OH 43205.

This research was supported by a grant from the Children's Hospital Research Foundation. are elevated in stressed newborns (2), the specific role of these substances in the neonate with septic shock and the possible beneficial effect of naloxone (an opiate antagonist) therapy have not been investigated. The objectives of this investigation were to study the circulatory alterations following infusion of live GBBS in newborn piglets and to determine the efficacy of naloxone in improving the cardiovascular performance in this animal model.

\section{METHODS}

Animal preparation. Eighteen newborn piglets (1-4 days of age) weighing $1.2-1.8 \mathrm{~kg}$ were anesthetized with pentobarbital $(25 \mathrm{mg} / \mathrm{kg}$ intraperitoneally). Supplemental barbiturate (5-10 $\mathrm{mg} / \mathrm{kg}$ intravenously) was given during the study to maintain adequate anesthesia. Rectal temperatures were maintained with electric heating pads and warming lights. An endotracheal tube was placed through a tracheotomy and the animal was ventilated with a Bourns LS 104 infant ventilator to maintain normal arterial blood gases.

Catheters were placed in the abdominal aorta (via femoral arteries), right atrium (via internal jugular vein), and left ventricle (via carotid artery). After a left thoracotomy the ductus arteriosus was ligated, a catheter was introduced into the main pulmonary artery, and an external electromagnetic blood flow transducer (Gould Electronics, Oxnard, CA) was placed around the main pulmonary artery.

Physiologic measurements. Statham p23d transducers were used for continuous measurement of MAP and phasic arterial pressure, mean PAP, and phasic pulmonary artery pressure, phasic left ventricular pressure, and CVP. LVEDP was obtained from the phasic arterial recordings. The left ventricular pressure signal was electronically differentiated with respect to time to obtain the maximum rate of rise of left ventricular pressure (dP/ dt $\max$ ) as a measure of cardiac contractility. The flow probe was connected to a Gould SP2202 Blood Flowmeter (Gould Electronics, Oxnard, CA) for measurement of pulmonary artery blood flow taken as equivalent to $\mathrm{CO}$. All other hemodynamic variables were recorded on a Gould 2600S recorder (Gould Electronics, Cleveland, $\mathrm{OH}) . \mathrm{CaO}_{2}$ and $\mathrm{CpO}_{2}$ as measured by the Lex $-\mathrm{O}_{2}-\mathrm{Con}$ analyzer (Lexington Instruments, Waltham, MD) were determined at baseline, at the end of the bacterial infusion, then hourly.

Bacterial preparation. A standard stock of serotype III GBBS (American Type Culture Collection no. 31475) was stored at $-60^{\circ} \mathrm{C}$ in sheep blood until ready for use. The day before the study, the organism was subcultured onto sheep blood agar and incubated at $37^{\circ} \mathrm{C}$ for 16 to $18 \mathrm{~h}$. On the morning of each study, colonies were skimmed from the surface, inoculated into ToddHewitt broth, and incubated for $3 \mathrm{~h}$ at $37^{\circ} \mathrm{C}$. The broth then underwent two cycles of centrifugation $(1600 \times g$ for $10 \mathrm{~min})$, with each cycle followed by resuspension of the bacterial pellet 
in sterile, nonpyrogenic saline. A concentration of approximately $2 \times 10^{9} \mathrm{CFU} / \mathrm{ml}$ was obtained by titrating to an absorbance of 0.8 on a spectrophotometer at a wavelength of $550 \mathrm{~nm}$. Viability counts of the bacterial infusate were verified with standard serial dilution and pour-plate techniques.

Experimental design. After a stabilization period of $1 \mathrm{~h}$ following surgery, all piglets received $15 \mathrm{ml} / \mathrm{kg}$ (corresponding to 2-4 $\times 10^{10} \mathrm{CFU} / \mathrm{kg}$ ) of the bacterial preparation intraarterially over $30 \mathrm{~min}$. Treated pigs $(n=9)$ were given naloxone $1 \mathrm{mg} / \mathrm{kg}$ at the end of the bacterial infusion followed by a continuous infusion of $1 \mathrm{mg} / \mathrm{kg} / \mathrm{h}$. Control animals $(n=9)$ received an equal volume of saline. Measurements were continued to a maximum of $5 \mathrm{~h}$ after the bacterial infusion.

At the conclusion of the experiment the small and large intestines were removed from four of the animals from each group and fixed in formalin. Sections were embedded in paraffin, stained with hematoxylin and eosin, and examined under light microscopy. The examiner was blinded as to the animal's treatment status.

Calculations and statistical analyses. SVR was calculated as follows:

PVR was calculated as follows:

$$
\mathrm{SVR}=(\mathrm{MAP}-\mathrm{CVP}) / \mathrm{CO}
$$

$$
\text { PVR }=(\text { PAP-LVEDP }) / C O
$$

$\mathrm{VO}_{2}$ was derived from the Fick equation:

$$
\mathrm{VO}_{2}=\left(\mathrm{CaO}_{2}-\mathrm{CpO}_{2}\right) \times \mathrm{CO}
$$

Analysis of variance for repeated measures was used to detect statistical significance within groups and between groups over time. Data taken from the record at 30-min intervals were used for the analysis. Fisher's exact test was used to compare the survival data between groups. Survival was defined as being alive at $5 \mathrm{~h}$ following the bacterial infusion. All variables are expressed as mean \pm SEM. A $p$ value of $<0.05$ was considered significant.

\section{RESULTS}

Baseline hemodynamic measurements and calculations did not differ significantly between groups. Approximately $1 \mathrm{~h}$ after the end of the bacterial infusion, both groups had a 20 to $30 \%$ decrease in their MAP which further declined in the control piglets, but was stabilized in the treated piglets (Fig. 1A). The difference between groups was significant $(p<0.02)$. The blood pressure response in the naloxone-treated pigs was not accompanied by a parallel increase in SVR. There was no significant difference in the systemic vascular resistance between groups; both groups showed an elevation during the bacterial infusion followed by a gradual return to baseline values (Fig. $1 B$ ).

CO was severely affected, declining by over $50 \%$ in both groups within minutes of the bacterial infusion (Fig. $1 C$ ). At the end of the bacterial infusion, both groups demonstrated a partial recovery in their $\mathrm{CO}$ which was more marked and prolonged in the naloxone-treated animals, but only transient in the controls. Although the difference in cardiac output did not reach statistical significance $(p>0.1)$, naloxone treatment tended to maintain and stabilize the $\mathrm{CO}$. The fall in $\mathrm{CO}$ in the control group was accompanied by a profound and steady fall in cardiac contractility (Fig. $1 D$ ). Naloxone treatment prevented this decrease and restored cardiac contractility toward baseline $(p<0.05)$.

The pulmonary artery pressure rose significantly in response to the bacterial infusion in both groups $(p<0.05)$ and slowly returned to baseline values (Fig. $1 E$ ). This was unaffected by naloxone treatment. The PVR demonstrated a similar trend in both groups (data not shown). In keeping with the abrupt decline in $\mathrm{CO}$, the $\mathrm{VO}_{2}$ fell in both groups during the bacterial infusion followed by a compensatory rise (Fig. $1 F$ ). Although not reaching statistical significance, naloxone treatment seemed to maintain the compensatory rise in $\mathrm{VO}_{2}$. There was no significant difference between groups for HR, LVEDP, CVP, or hematocrit (data not shown).

Representtive sections of the small and large intestine were examined by light microscopy. One of the control animals demonstrated evidence of small intestinal ischemia with confluent mucosal and submucosal hemorrhages and breakdown of mucosal crypts. Two other control piglets and one naloxone-treated piglet had less severe changes limited to congestion of the lamina propria of the small or large intestine. No severe hemorrhage or crypt disruption was evident in the naloxone-treated animals.

Naloxone significantly improved survival with seven of nine treated animals versus only three of nine control animals alive for at least $5 \mathrm{~h}$ after the end of the bacterial infusion $(p<0.05)$ (Fig. 2).

\section{DISCUSSION}

The hemodynamic changes that occur during sepsis or endotoxemia in newborn animals have only recently been examined. Endorphins may be partly responsible for these changes (3). These substances are stored in the anterior pituitary gland and share a common proopicortin precursor with ACTH $(4,5)$. Several investigators have documented elevations of these opioid peptides in various shock states (3). Furthermore, exogenous administration of these peptides intravenously or intracerebrally exert dramatic cardiovascular effects (3). They are thought to act on central opioid receptors to influence autonomic outflow and inhibit sympathomedullary discharge (4). However, a direct effect on opiate receptors in the heart, vasculature, and lungs has not been conclusively disproved (3).

One of the most striking hemodynamic changes observed in our study was the rapid and persistent reduction in $\mathrm{CO}$ induced by the bacterial infusion. There were no concomitant changes in heart rate or LVEDP (a measure of preload) to account for this decline in CO. Similarly, mechanical interference with myocardial function resulting from severe pulmonary hypertension seems unlikely. The decline in $\mathrm{CO}$ occurred before any significant elevation in PAP and persisted despite a return of PAP to values similar to baseline. Other investigators have made similar observations $(6,7)$. The reduced $\mathrm{CO}$ most likely represents a change in the intrinsic contractile state of the heart as reflected in the reduced $\mathrm{LV} \mathrm{dP} / \mathrm{dt}$ max, which may be altered by changes in preload (8). Since LVEDP did not change significantly during the study, the reduced $\mathrm{LV} \mathrm{dP/dt} \mathrm{max} \mathrm{suggests} \mathrm{a} \mathrm{true} \mathrm{decline} \mathrm{in}$ myocardial contractility.

Pulmonary arterial hypertensive responses during bacterial or toxin infusion have been described in piglets $(6,9,10)$ and in the lamb (11). As in our study, the elevation in PAP and PVR was rapid but transient, increasing in response to bacterial or endotoxin infusion, and returning to baseline values within several minutes $(6,11)$. Similar responses are observed in mature animals $(11-13)$.

Naloxone, a specific opiate antagonist with no agonist activity, has been shown to be effective in experimental septic shock using adult animals $(1,4,14)$. The cardiovascular effects of naloxone are stereospecific, acting to facilitate sympathomedullary outflow through an antagonism of endorphins at sites within the central nervous system (5). An intact sympathetic nervous system and adrenal gland is required for naloxone to produce its therapeutic effects (4). A few anecdotal reports have documented the drug's effectiveness in children and adults with septic shock (16-20).

Our study confirms that naloxone attenuates septic shock and extends this observation to newborn swine. Although these animals were subjected to a relatively large and rapidly administered bacterial inoculum (a dose and rate that was necessary to consistently produce hypotension), naloxone significantly improved MAP and cardiac contractility and tended to ameliorate the decline in $\mathrm{CO}$ and $\mathrm{VO}_{2}$. Lobe et al. (21) found evidence of gut ischemia associated with naloxone treatment of peritonitis-induced septic shock in piglets. This is in contrast to other reports showing an improvement in splanchnic blood flow and a reversal of local tissue hypoxia $(22,23)$. In our study, naloxone improved MAP without altering SVR, indicating an overall improvement 
A

MEAN ARTERIAL PRESSURE

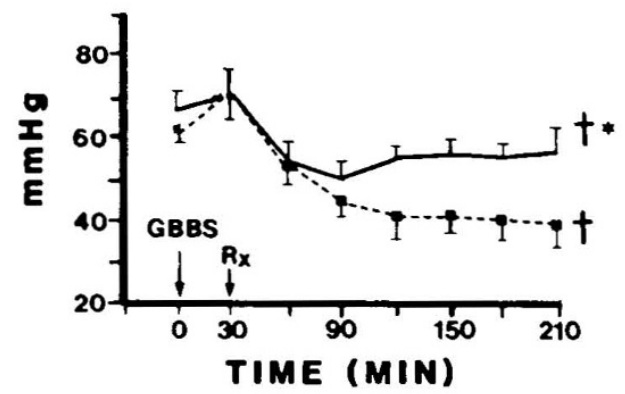

C

CARDIAC OUTPUT

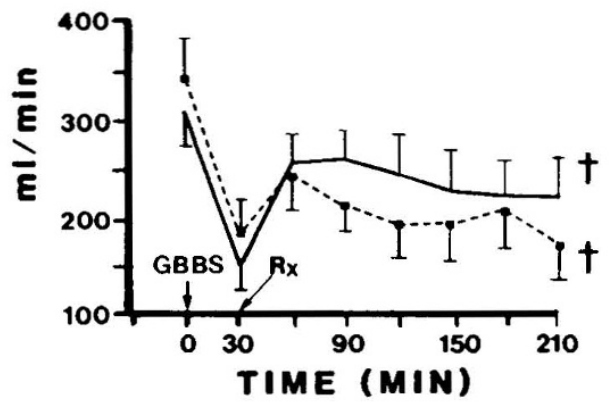

$\mathbf{E}$
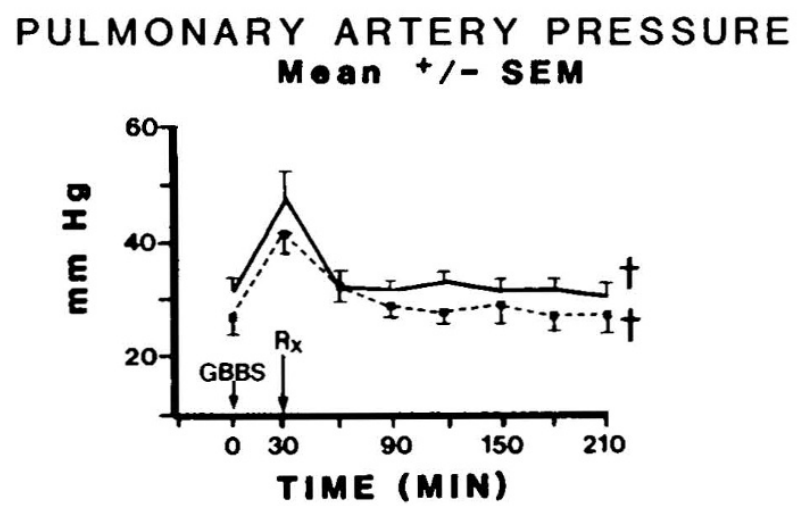

B
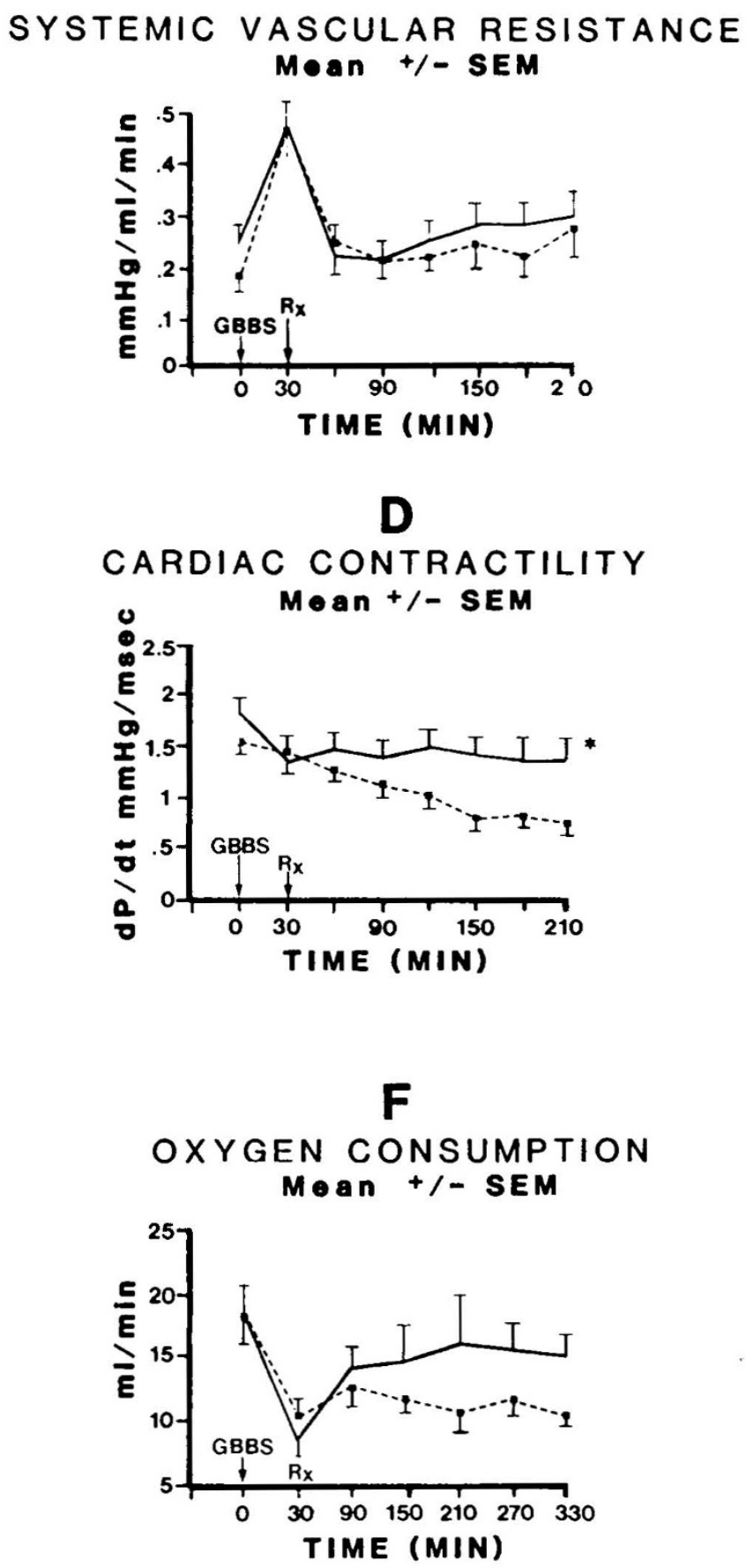

\section{- NALOXONE
CONTROL}

Fig. 1. Hemodynamic changes in the control and naloxone-treated groups: $A$, MAP; $B$, SVR; $C, \mathrm{CO} ; D, \operatorname{cardiac} \mathrm{dP} / \mathrm{dt} ; E, \mathrm{PAP} ; F, \mathrm{VO}{ }_{2} .+$ denotes significant difference with respect to time; * denotes significance between groups; and, $R x$ denotes treatment with either naloxone or saline

in peripheral perfusion. This is supported by the histologic studies of the animals' intestinal tract. None of the naloxone-treated animals had evidence of hypoxic-ischemic changes.

Several caveats are in order regarding naloxone therapy in septic shock. Although animal studies and anecdotal reports in humans attest to the drug's effectiveness, recent controlled trials in adult humans have not been promising. Groeger et al. (24) found that only $50 \%$ of patients with septic shock responded to a $0.3 \mathrm{mg} / \mathrm{kg}$ dose of naloxone with an elevation of blood pressure and SVR and no change in CO. All of the responders were given naloxone before prolonged hypotension and acidosis had developed, a clinical luxury that is rarely present in neonatal sepsis. Recent reports have demonstrated that naloxone in similar doses had no significant effect on mean blood pressure, $\mathrm{CO}$, or survival in septic patients $(25,26)$. Furthermore, adverse reactions after naloxone therapy including severe hypotension, pulmonary 


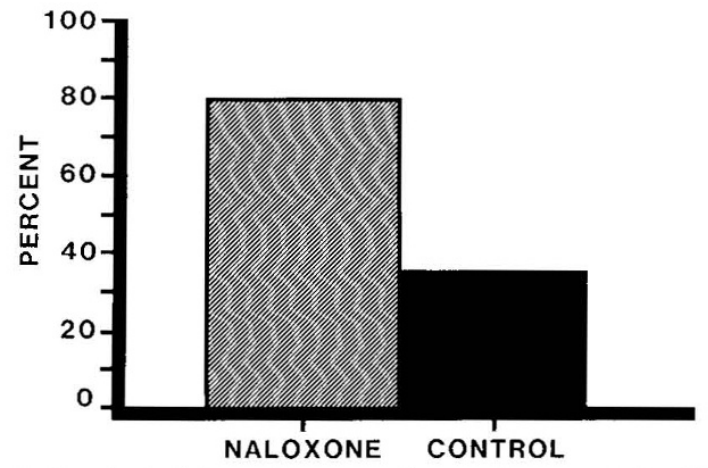

Fig. 2. Survival of the naloxone and control groups. The difference is significant $(p<0.05)$.

edema, and seizures have been reported $(26,27)$. Although shown to be safe even if given in massive doses to normal volunteers (28), naloxone may have undesirable consequences in the critically ill patient.

Species differences in opiate receptors or cardiovascular physiology may account for the inconsistent results of naloxone therapy in humans as compared to animals (29). Nevertheless, the piglet's cardiovascular system is physiologically similar to the human neonate (30) and the appropriateness of comparing this septic shock model to the human newborn condition has been addressed (9). Further comparisons are hampered by the lack of knowledge regarding the ontogeny of the various opiate receptors in the human newborn or piglet. Nevertheless, this model suggests that naloxone's binding to opiate receptors may be important in improving the cardiovascular performance during sepsis in newborns. Further investigations are warranted prior to initiating this as routine therapy.

Acknowledgments. The authors thank Mario Marcon, Ph.D., for his technical assistance, Mrs. Dawn Penn for her secretarial assistance, and Richard E. McClead, M.D. for his careful review of this manuscript.

\section{REFERENCES}

1. Faden AI, Holaday JW 1980 Experimental endotoxic shock: The pathophysiologic function of endorphins and treatment with opiate antagonists. J Infect Dis 142:229-238

2. Wardlaw SL, Stark RI, Baxi L, Frantz AG 1979 Plasma B-endorphin and Blipotropin in the human fetus at delivery: correlation with arterial $\mathrm{pH}$ and $\mathrm{pCO}_{2}$. J Clin Endocrinol Metab 49:888-891

3. Holaday JW 1983 Cardiovascular consequences of endogenous opiate antagonism. Biochem Pharmacol 32:573-585

4. Holaday JW 1983 Cardiovascular effects of endogenous opiate systems. Ann Rev Pharmacol Toxicol 23:541-594

5. Holaday JW 1983 Endorphins in shock and spinal injury; therapeutic effects of naloxone and thyrotropin-releasing hormone. In Lefer AM, Schumer W (eds) Molecular and Cellular Aspects of Shock and Trauma. Alan R. Liss, New York, pp 167-184

6. Runkle B, Goldberg RN, Streitfeld MM, Clark MR, Buron E, Setzer ES,
Bancalari E 1984 Cardiovascular changes in group B streptococcal sepsis in the piglet: response to indomethacin and relationship to prostacyclin and thromboxane $\mathrm{A}_{2}$. Pediatr Res 18:874-878

7. Peevy KJ, Chartrand SA, Wiseman HJ, Boerth RC, Olson RD 1985 Myocardial dysfunction in group B streptococcal shock. Pediatr Res 19:511-513

8. Mahler F, Ross J, O'Rourke RA, Covell JW 1975 Effects of changes in preload, afterload and inotropic state on ejection and isovolumic phase measures of contractility in the conscious dog. Am J Cardiol 35:626-634

9. Meadow WL, Meus PJ 1984 Hemodynamic consequences of tolazoline in neonatal group B streptococcal bacteremia: an animal model. Pediatr Res 18:960-965

10. Graybar GB, Lyrene RK, Godoy G, Barefield E, Sams JEP, Gray B, Phillips JB 1985 Pulmonary hypertensive response to group B streptococcus is blocked by thromboxane synthesis inhibition but not leukotriene synthesis inhibition or endorphin blockade. Crit Care Med 13:294(abstr)

11. Rojas J, Larsson LE, Hellerqvist CG, Brigham KL, Gray ME, Stahlman MT 1983 Pulmonary hemodynamic and ultrastructural changes associated with group B streptococcal toxemia in adult sheep and newborn lambs. Pediatr Res 17:1002-1008

12. Schuette AH, Huttemeier PC, Hill RD, Watkins WD, Wonders TR, Kong D, Zapol WM 1984 Regional blood flow and pulmonary thromboxane release after sublethal endotoxin infusion in sheep. Surgery 95:444-452

13. Mamazza J, Hinchey EJ, Chiu RC 1984 The pulmonary effects of opiate blockade in septic shock. J Surg Res 36:625-630

14. Gahos FN, Chiu RCJ, Hinchey EJ, Richards GK 1982 Endorphins in septic shock: Hemodynamic and endocrine effects of an opiate receptor antagonist and agonist. Arch Surg 117:1053-1057

15. Raymond RM, Harkema JM, Stoffs WV, Emerson TE 1981 Effects of naloxone therapy on hemodynamics and metabolism following superlethal dosage of E. coli endotoxin in dogs. Surg Gynecol Obstet 152:159-162

16. Dirksen R, Otten MH, Wood GJ, Verbaan CJ, Haalebos MMP, Verdouw PV, Nijhius GMM 1980 Naloxone in shock. Lancet 2:1360-1361

17. Peters WP, Friedman PA, Johnson MW, Mitch WE 1981 Pressor effect of naloxone in septic shock. Lancet 1:529-532

18. Swinburn WR, Phelan P 1982 Response to naloxone in septic shock. Lancet 1:167

19. Tiengo M 1980 Naloxone in irreversible shock. Lancet $2: 690$

20. Furman WL, Menke JA, Barson WJ, Miller RR 1984 Continuous naloxone infusion in two neonates with septic shock. J Pediatr 105:649-651

21. Lobe TE, Dobkin ED, Bhatia J, Oldham KT, Linares HA, Traber DT 1985 Naloxone induced gut ischemia during resuscitation of experimental neonatal septic shock. Pediatr Res 19:143A(abstr)

22. Law WR, Gamma-Filho P, Donahue P, Ferguson J 1984 Naloxone improves splanchnic circulation during endotoxin shock in rats. Circ Shock 12:64(abstr)

23. Rees M, Payne JG, Bowen JC 1982 Naloxone reverses tissue effects of live E. coli sepsis. Surgery 91:81-86

24. Groeger JS, Carlon GC, Howland WS 1983 Naloxone in septic shock. Crit Care Med 11:650-654

25. Demaria A, Heffernan JJ, Grindlinger GA, Craven DE, McIntosh TK, McCabe WR 1985 Naloxone versus placebo in treatment of septic shock. Lancet 1:1363-1365

26. Rock P, Silverman H, Plump D, Kecala Z, Smith P, Michael JR, Summer W 1985 Efficacy and safety of naloxone in septic shock. Crit Care Med 13:2833

27. Chugani HT, Ackermann RF, Chugani DC, Engel J 1984 Opioid-induced epileptogenic phenomena: Anatomical, behavioral, and electroencephalographic features. Ann Neurol 15:361-368

28. Jasinski DR, Martin WR, Haertzen CA 1967 The human pharmacology and abuse potential of $\mathrm{N}$-allylnoroxymorphone (naloxone). J Pharmacol Exp Ther 157:420-426

29. Hinshaw LB, Beller BK, Chang ACK, Flournoy DJ, Lahti RA, Passey RB, Archer LT 1984 Evaluation of naloxone for therapy of E. coli shock: Species difference. Arch Surg 119:1410-1418

30. Gootman PM, Gootman N, Turlapaty PDMV, Yao AC, Buckley BJ, Altura BM 1981 Autonomic regulation of cardiovascular function in neonates. Ciba Found Symp 83:70-93 